\title{
Matías Maestro, José del Pozo y el arte en Lima a inicios del siglo XIX
}

\author{
Ricardo Kusunoki Rodríguez \\ Universidad Nacional Mayor de San Marcos, Perú \\ rkusunoki52@hotmail.com
}

\begin{abstract}
Resumen
El artículo es un acercamiento al arte limeño de inicios del siglo XIX, centrado en las figuras de Matías Maestro y José del Pozo. Se intenta ir más allá de definir este período como neoclasicismo, al centrar el análisis en las motivaciones de los comitentes y artistas. Para ello se ha recurrido a distintos tipos de documentos, sean cuentas de cofradías, sermones o periódicos, contextualizando así las piezas artísticas. En una sociedad corporativa y monárquica, el impacto de la Ilustración y el retorno a los modelos grecolatinos no generó un neoclasicismo en el sentido estricto, sino, como en toda manifestación periférica, la superposición de estratos estilísticos. El "buen gusto" impuesto por la labor de Matías Maestro y José del Pozo significó en realidad la subordinación de las manifestaciones artísticas locales a las de la Metrópoli, al imponerse dos artistas españoles y sin formación local en el gusto oficial y de élite.
\end{abstract}

Palabras clave: ARTE, LIMA, SIGLO XIX, MATÍAS MAESTRO, JOSÉ DEL POZO.

\begin{abstract}
The article is an approach to the art of Lima during the early 19th century, focused on the figures of Matías Maestro and Jose del Pozo. It tries to go beyond defining this period as Neoclassic by centering the analysis on the motivations of the comitentes and artists. The article rests on different types of documents, including accounts of brotherhoods, sermons and journals, thus giving a context to the artistic pieces. In a corporative and monarchic society, the impact of the Illustration and the return to Greco Latin models did not generate a Neoclassicism in the strict sense, but, as it is usual of peripheral manifestations, the superposition of stylistic layers. The "good taste" imposed by the works of Matías Maestro and Jose del Pozo meant in fact the subordination of local artistic manifestations to those of the Metropolis, while the two Spanish artists prevailed without a formation in the local official taste of the elite.
\end{abstract}

Key Words: ART, LIMA, 19TH CENTURY, MATÍAS MAESTRO, JOSE DEL POZO. 
El panorama de las artes en Lima a inicios del siglo XIX es aún impreciso, en parte debido a la pobre calidad de la producción artística de esta época y al consiguiente desinterés por su estudio ${ }^{1}$. Pero definitivamente no ha ayudado la facilidad con que el rótulo de neoclásico asignado a estas obras puede librarnos de un análisis más profundo. A primera vista, el "neoclasicismo" parece confirmado por la obsesión con que las fuentes escritas de inicios del siglo XIX repugnan lo "churrigueresco" en nombre del lugar común de la estética ilustrada: el "buen gusto". Sin embargo, es visible la fuerte carga barroca que pervive en obras usualmente definidas como neoclásicas ${ }^{2}$. En este sentido, se genera una contradicción: las fuentes escritas parecieran afirmar una ortodoxia clasicista que las propias obras niegan.

A inicios del siglo XIX, fue una constante en los comentarios sobre arte en Lima el desprecio por la oscuridad y abigarramiento decorativos, cuyo destierro era exigido en nombre del buen gusto. Este término designaba a las obras que poseían aquella gracia sublime cuyo principal modelo a seguir era el arte de la antigüedad clásica. Como ha señalado Rosario Assunto, la gracia neoclásica se diferenciaba de la rococó al estar dirigida a la razón y no a los sentidos ${ }^{3}$. Frente a un arte puramente sensorial, el neoclasicismo buscaba un placer intelectual que se apoyaba en la simplicidad formal y en la claridad del mensaje. En Lima, en nombre de esta claridad, la repulsa a lo churrigueresco fue tácita, de la misma forma que la defensa de la imitación del arte grecolatino. Y el "buen gusto" en Lima, impulsado por el arzobispo Juan Domingo Gonzáles de la Reguera en las obras de la Catedral a fines del siglo XVIII, halló en el presbítero vasco Matías Maestro su exponente más calificado ${ }^{4}$.

Arquitecto diseñador, Matías Maestro nació en Vitoria (Álava), el 22 de febrero de 1766. A su llegada a Lima se dedicó al comercio, y en 1793 recibió órdenes sagradas. Protegido del arzobispo Gonzáles de la Reguera, Maestro devino, a inicios del siglo XIX, en una suerte de árbitro del buen gusto de la ciudad. Las distintas congregaciones religiosas, así como el virrey Fernando de Abascal, le encargaron el diseño de gran número de obras, entre retablos y construcciones, e incluso el Cementerio General (1808).

\footnotetext{
1 Agradezco a Natalia Majluf, Amelia Castro y Luis Eduardo Wuffarden por las observaciones y comentarios que hicieron a este artículo.

2 Ricardo Kusunoki, "Barroco y pintura limeña a inicios del siglo XIX", Uku Pacha. Revista de Investigaciones históricas (Lima), año 5, núm. 9 (2006): 101-110.

${ }^{3}$ Rosario Assunto, La antigüedad como futuro. Estudios sobre la estética del neoclasicismo europeo, trad. Zósimo Gonzáles (Madrid: Visor, 1990), 27-57.

4 "Yten, declaro que las fabricas de las torres empezó vajo la dirección del Arquitecto D. Ygnacio Martorell y continuo despues vajo de la del Presvitero D. Mathias Maestro, quien corrio igualmente con todas las demas obras hasta su conclusión" (1805), Archivo Arzobispal de Lima (Lima), Papeles Importantes, exp. 30, leg. 27.
} 
La figura de Maestro resulta fundamental para entender las particularidades del clasicismo local que se configuró desde fines del siglo XVIII y que alcanzó un punto culminante durante el gobierno de Abascal. Los diferentess estratos estilísticos coexistentes en el arte de las dos primeras décadas del siglo XIX son reflejo de los distintos "tiempos" presentes en una misma actualidad colonial, cada cual con un mayor o menor retraso de la "hora" de la metrópoli ${ }^{5}$. A nivel social, los híbridos generados entre la Ilustración y la herencia católica y monárquica ya han sido puestos de manifiesto por Annick Lempérière, quien señala la mezcla de republicanismo y sociedad corporativa a inicios de la vida independiente mexicana ${ }^{6}$. Los distintos estratos presentes en la obra de Maestro son, de la misma forma, evidencia de la adopción de un vocabulario formal que se pretende calcado de la antigüedad grecolatina, subordinado a las necesidades propagandísticas del Antiguo Régimen.

\section{Barroco y sociedad}

Durante la primera mitad del siglo XVIII, se concebía la sociedad como un cuerpo formado por distintas "naciones" con una identidad propia. La pluriculturalidad católica propia del régimen Habsburgo permitía y hasta impulsaba la diversidad de variantes estilísticas barrocas ${ }^{7}$. Pero a partir de la aparición de las ideas modernas y de la implantación de las reformas borbónicas, hacia la segunda mitad del siglo XVIII, el poder oficial busca la homogenización y reducción de las diferencias culturales. En el plano estético, el referente a seguir es el arte clásico, cuya imitación para la conformación de un gusto oficial será impulsada desde la Metrópoli por el rey Carlos III y los sectores ilustrados españoles, quienes comparten las mismas críticas contra el estilo churrigueresco o el uso de la columna salomónica. La Ilustración, que oponía la racionalidad al principio de autoridad escolástico, atacó las manifestaciones artísticas barrocas como contrarias a la noble simplicidad y claridad racionales. La libertad formal permitida por el Barroco fue criticada acremente, contraponiéndola a una arquitectura normada por la razón.

Frente a los intentos criollos que durante la segunda mitad del siglo XVIII buscaron configurar un clasicismo artístico con referentes locales, a fines de este

\footnotetext{
${ }^{5}$ Pablo Macera, La pintura mural andina. Siglos XIV- XIX (Lima: Milla Batres, 1993), 20.

${ }^{6}$ Véase Annick Lempérière, "De la república corporativa a la nación moderna. México (1821-1860)", en Inventando la nación. Iberoamérica. Siglo XIX, eds. Antonio Annino y Francois-Xavier Guerra (México: Fondo de Cultura Económica, 2003): 316-346.

7 "El Barroco no sustituye unas tradiciones por otras. Más bien las acumula, las superpone, creando complejos estratos de contenidos paralelos y simultáneos". Ramón Mujica, "Arte e identidad: las raíces culturales del Barroco peruano", en El Barroco peruano (Lima: Banco de Crédito del Perú, 2002), 1-57.
} 
siglo la dirección del gusto será asumida por el poder oficial ${ }^{8}$. Ya entrado el siglo XIX, dentro del proceso de modernización impulsado por Abascal (1806-1816), se buscará en arquitectura la homogenización estilística según los órdenes clásicos y en la pintura el uso de un vocabulario formal académico, todo dirigido a la formación de un gusto oficial y a la desaparición de las manifestaciones artísticas populares. En este marco, el Cementerio General y la Escuela de Medicina (1808) se realizarán en el nuevo estilo clasicista bajo la dirección de Matías Maestro. Ambas obras reflejaban el sesgo secular y racional que fue asumiendo la cultura como parte del proceso de modernización, dentro de una sociedad corporativa, y un discurso oficial absolutista con fuerte componente religioso9. Esta actitud reaccionaria se hace más nítida si se contrapone con la de sectores liberales que enarbolan a la razón para la defensa de las libertades individuales y de una nueva actitud frente al poder ${ }^{10}$.

Así, una edificación tan emblemática de la Ilustración en Lima, como el Cementerio General, responde plenamente a una concepción corporativa de la sociedad (Figura 1). En el marco del discurso ilustrado, la construcción de un cementerio fuera de la ciudad respondía a la necesidad de higiene pública e implicaba romper con la tradición arraigada de los entierros en iglesias. Diseñado por Matías Maestro e inaugurado en 1808, la estructura del Cementerio General aludía explícitamente a la antigüedad clásica, al tomar como modelo los columbarios romanos. Formalmente, mas la organización del camposanto no trajo consigo grandes novedades.

\footnotetext{
${ }^{8}$ Ricardo Kusunoki Rodríguez, "De Ruiz Cano a Unanue: Arte y reivindicación criolla en Lima (1755-1806)", Dieciocho (Virginia), 29, núm. 1 (2006): 107-120.

${ }^{9}$ Marie-Danielle Demélas, La invención política. Bolivia, Ecuador, Perú en el siglo XIX (Lima: Instituto Francés de Estudios Andinos; Instituto de Estudios Peruanos, 2003).

${ }^{10}$ Víctor Peralta Ruiz, En defensa de la autoridad: Politica y cultura bajo el gobierno del virrey Abascal, Perú 1806-1816 (Madrid: Consejo Superior de Investigaciones Científicas; Instituto de Historia, 2002), 52.
} 


\section{Figura 1}

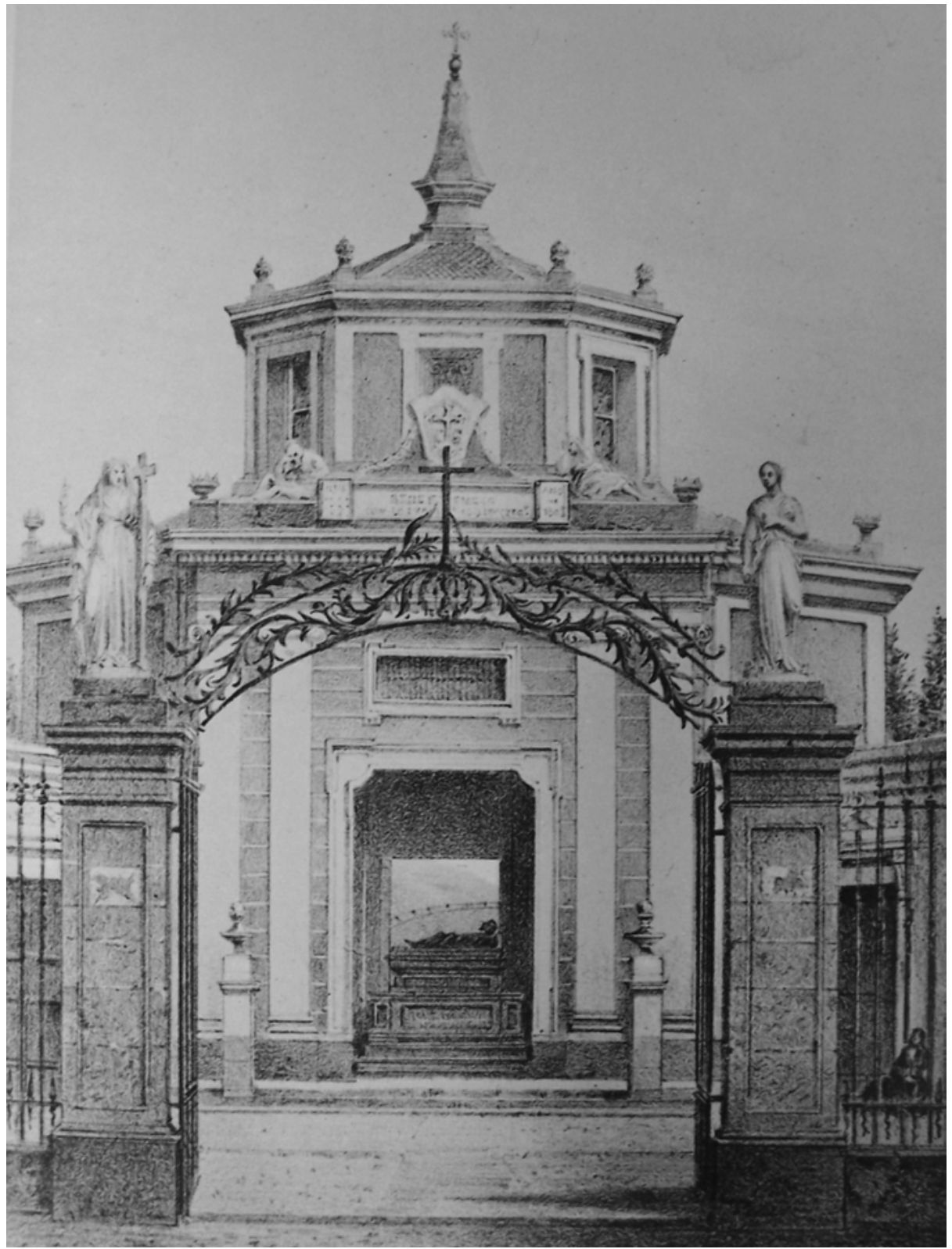

Matías Maestro. Capilla del Cementerio General de Lima (desaparecida), 1808. 
El diseño del Cementerio constituye la representación simbólica de una sociedad corporativa, donde se perennizaba no la memoria de los individuos, sino la de las corporaciones que conformaban el cuerpo social, las que fueron beneficiadas con un número determinado de nichos entregados en propiedad. Esto implicaba el derecho a un lugar diferenciado, concebido como un privilegio exclusivo, no como una compra. Cada departamento o cuartel correspondía a sectores de la élite específicos, los que tenían la posibilidad de que, al tiempo de evacuar los nichos, pudiesen depositar los restos en osarios particulares ubicados en los lugares asignados ${ }^{11}$. La distribución del cementerio demarcaba jerarquías, y cada cual ocupaba un lugar determinado por su rango o pertenencia a una corporación.

El reglamento de 1808 prohibía que en las lápidas figurasen "trofeos, epitafios, y toda singularidad que exceda de un escudo sencillo, con el título de pertenencia, escrito en la parte superior con que se distinguirán" ${ }^{12}$. La pertenencia alude no al difunto sepultado, sino a la familia o corporación propietaria del nicho, por ello en cada sección las lápidas eran todas iguales, al no constar las referencias individuales ${ }^{13}$. La prohibición de excesos ornamentales en las lápidas y la búsqueda de homogenizar su aspecto están claramente relacionadas con el estilo neoclásico. Pero con ello el Cementerio se plantea como un símbolo de una sociedad estamental y rígida, en la medida en que son las corporaciones las que se nombran y no los individuos. Era la cristalización de un orden social ideal, concebido como un cuerpo rígidamente compartimentado e inamovible ${ }^{14}$. Los cadáveres de la élite, indiferenciados en los osarios particulares, no distaban de aquellos que, de la misma forma, habían sido sepultados en las criptas particulares de iglesias y conventos.

\section{Del Barroco en la pintura: la obra de José del Pozo}

\footnotetext{
${ }^{11}$ Reglamento provisional acordado por el Ecmo. Señor Don José Fernando de Abascal y Sousa con el Illmo. Señor Doct. D. Bartolomé María de las Heras para la apertura del Cementerio General de esta ciudad (Lima: Real Casa de Niños Expósitos, 1808), 3.

${ }^{12}$ Ibídem.

${ }^{13}$ El concepto contractual de la sociedad, es decir, un conjunto de individuos iguales entre sí reunidos por un contrato social, se esboza en las adiciones al reglamento del cementerio, publicadas en 1810, donde se establece un sector destinado a nichos perpetuos, adquiridos por compra. Eran los únicos nichos que llevaban el nombre del difunto y un epitafio, señal clara de la importancia que iba asumiendo el individuo en una sociedad corporativa. Sin embargo, el mismo reglamento establece que solo se franquearían hasta redimir los capitales que gravaban su fábrica o para costear una ampliación. José Fernando de Abascal, "Panteón", Minerva Peruana (Lima), 1 (6 de enero de 1810): 7-8.

${ }^{14}$ Reglamento, 4. El reglamento dejaba claro que solo se podía dar propiedad de nicho a los "que por patronato tubiesen sepultura separada en las Iglesias, y a los Títulos de Castilla, que la pidieren en su respectiva division".
} 
Una construcción tan emblemática del discurso ilustrado como la del Cementerio puede servir perfectamente a las necesidades de una sociedad corporativa y adoptar un lenguaje ornamental clásico. La pintura, en cambio, al no poder remitirse a modelos grecolatinos hará explícita las limitaciones de un "neoclasicismo" en el medio local. La intención oficial de dirigir el gusto se hizo visible en el ataque a las manifestaciones artísticas populares que hacían uso del espacio público. El bando del virrey, del 10 de octubre de 1806, ordenaba borrar "Las ridículas figuras y letreros indecentes, que los pulperos hacen pintar en las paredes exteriores", por dar "una idea que no corresponde a la civilidad y decoro de este vecindario"15. Civilidad y "buen gusto" se dan de la mano bajo el ojo vigilante de la autoridad virreinal.

Llegado a Lima en 1789 con la expedición Malaspina, el pintor sevillano José del Pozo fue colaborador inseparable de Maestro en su proceso de reformas estilísticas. Se ha señalado el carácter "barroco" de la obra de Pozo en una fecha tan tardía como inicios del siglo XIX ${ }^{16}$. Sin embargo, la constante colaboración de Pozo con Maestro, que se puede documentar entre 1807 y 1828, evidencia la gran estima que por la labor del sevillano tuvo el presbítero. Una de las obras realizadas por Pozo por mediación de Maestro, en 1820, es el enorme lienzo ubicado en el transepto de la Iglesia de Santo Domingo, Los Desposorios Místicos de Santa Rosa, "obra del Mayor Mérito" que costó 200 pesos (Figura 2) ${ }^{17}$.

\footnotetext{
${ }^{15}$ José Fernando de Abascal, "Bando", Minerva Peruana extraordinaria (Lima), 40 (10 de octubre de 1806).

16 "El último pincel barroco de la ciudad". Ernesto Sarmiento, El arte virreinal en Lima (Lima: Arica, 1971), 71. Véase también Jorge Bernales Ballesteros, "La pintura en Lima durante el virreinato", en Pintura en el Virreinato del Perú (Lima: Banco de Crédito del Perú, 2002), 66.

17 Miguel Antonio Vértiz, "Cuenta particular que yo Don Miguel Antonio de Vertis presento a la M Y y V. Hermandad y Archicofradía de Nuestra Madre y señora del Rosario de los Españoles [...] respecto a los gastos y limosnas colectados en la Novena de Rogativa que desde el día 19 hasta el 28 de noviembre del presente año se ha hecho en la Santa Iglesia Catedral [...]" (1820), Archivo de la Beneficencia Pública de Lima -en adelante ABPL- (Lima), Libro de Cuentas de la Archicofradía de N. S. del Rosario (1819-1830), núm. 8064, s.f. El dinero fue parte de una colecta realizada al sacarse la imagen de la Virgen del Rosario a la Catedral, para las rogativas por haber desembarcado los patriotas en Pisco, y la cuenta señala un pago por "el lienzo grande" de la capilla. Al lienzo de Los Desposorios pareciera aludir la descripción de la iglesia realizada por Casimiro Novajas, sin embargo también menciona otro cuadro ubicado frente a este, del cual no existe la menor referencia, aparte de ese texto. Probablemente se trate de obras que fueron proyectadas pero que no se llegaron a realizar. Casimiro Novajas, Rasgo épico. El vergel dominicano (Lima: Casa Real de Niños Expósitos, 1807), octavas 17 y 18.
} 
Figura 2

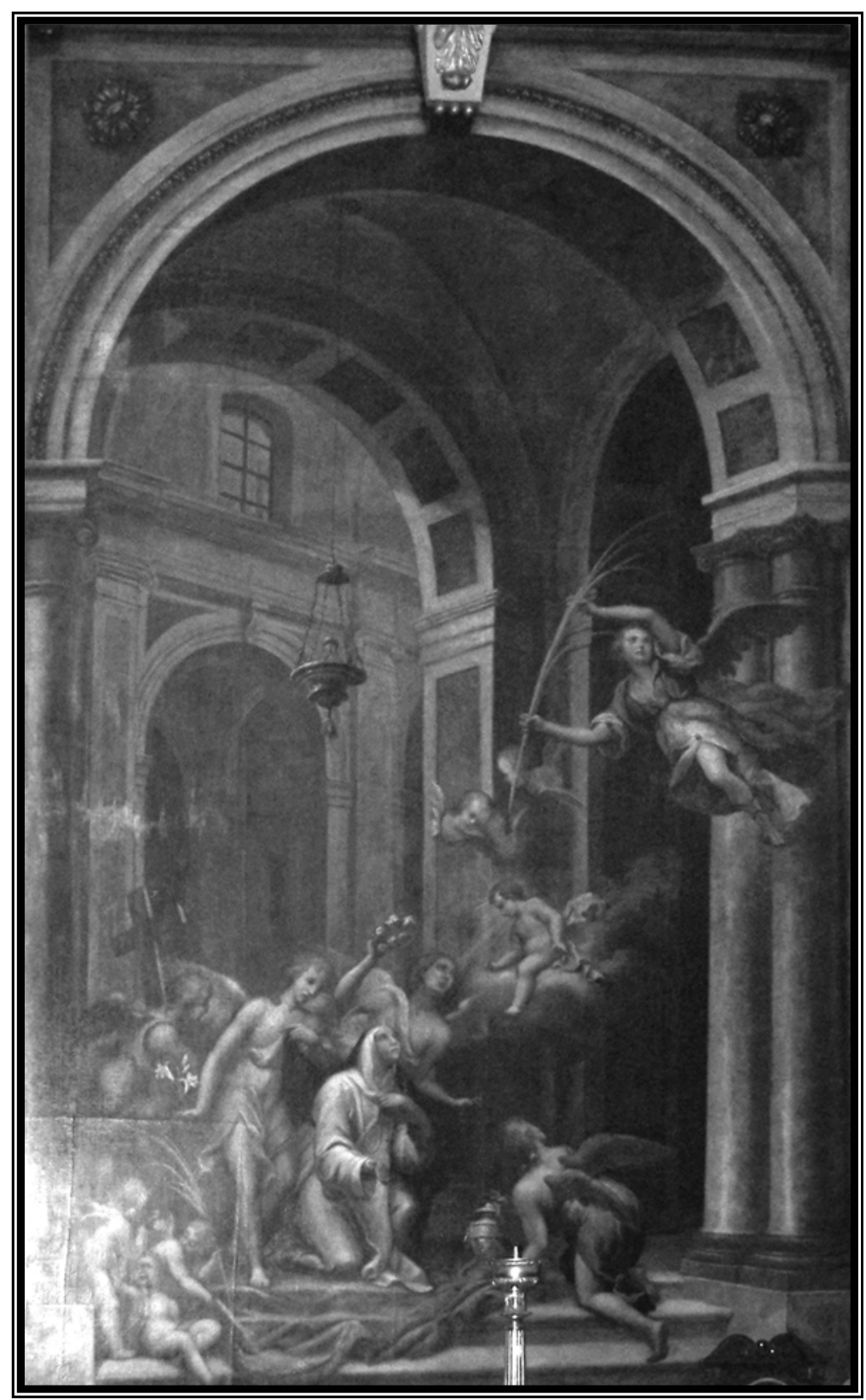

José del Pozo. Desposorios Místicos de Santa Rosa. Lima, 1820. Iglesia de Santo Domingo, Lima. 
En los proyectos decorativos de Maestro, los encargos de importancia casi en forma exclusiva fueron dados a Pozo, con lo que se desplazó a los pintores locales. Esto muestra que el presbítero no consideraba asincrónica su labor de diseño ni efectismos de la pintura del sevillano ${ }^{18}$. La necesidad de impacto visual es una constante en las obras de formatos grandes del pintor sevillano. En 1807, Pozo recibe 109 pesos de manos del presbítero por la ejecución de "un lienzo transparente para la ventana del recamarín" del retablo de la Virgen del Rosario, en la Iglesia de Santo Domingo ${ }^{19}$. El uso de transparentes, muy del gusto barroco, estuvo generalizado en Lima a inicios del siglo XIX, y su difusión pareciera ser obra del presbítero. Maestro buscaba estos efectismos en los diseños de sus retablos, e inclusive una de las pocas menciones de pintura de su mano se refiere a un lienzo transparente realizado por él para el mismo retablo en $1814^{20}$.

Sabemos por carta enviada el 17 de febrero de 1824, que Maestro intermedió en la elaboración de dos lienzos ovales hechos por Pozo para el retablo de Nuestra Señora del Rosario, en la Iglesia de Santo Domingo, aún existentes ${ }^{21}$. Frente a sus acostumbrados lienzos apoteósicos de grandes formatos, estos lienzos pequeños son verdaderas imágenes de devoción realizadas con una factura académica.

Las composiciones en escorzos violentos, el gusto por los trampantojos, la teatralidad y carácter apoteósico son una constante en la obra pictórica de Pozo. Para la época, esta obra pasaba por clásica, al igual que los diseños con claras reminiscencias barrocas y rococó de los retablos del presbítero ${ }^{22}$. Imitar los antiguos se constituye en un requisito tácito para las artes en los impresos de esos años. La capilla del Cementerio, obra de Maestro, era de "el gusto de los Templos

\footnotetext{
${ }^{18}$ Por las referencias de archivo en el caso de la Archicofradía del Rosario entre 1807 y 1824, es visible que Maestro sólo realizó intervenciones mínimas como pintor y dejaba los trabajos importantes en manos de Pozo, con lo que desplazaba a los pintores locales activos para la fecha, como Pedro Díaz, Julián Jayo o Xavier de Aguilar.

19 Juan Macho, "Cuentas del Mayordomo don Juan Macho" (1807), ABPL (Lima), Libro de Cuentas de la Archicofradía de N. S. del Rosario (1807-1813), núm. 8042.

${ }^{20}$ Tomás de la Casa y Piedra, "Cuentas del Doctor Tomás de la Casa y Piedra" (1814), ABPL (Lima), Libro de Cuentas de la Archicofradía de N. S. del Rosario (1814-1818), núm. 8046, recibo 20.

${ }^{21}$ Maestro señala: "Al portador d Jose del pozo he encargado la Composin ${ }^{\text {n }}$ de los dos liensos de $\mathrm{N}^{\mathrm{a}}$ y $\mathrm{S}^{\mathrm{a}}$ y $\mathrm{S}^{\mathrm{ta}}$ Rosa que se han de colocar en el Altar para que permanescan con la recomenda ${ }^{\mathrm{n}}$ de su acertado pincel”. Sebastián Comparet, "Cuenta de gastos en la Obra del Altar de la Virgen del Rosario a Cargo de Don Sebastian Comparet Mayordomo Bolsero desde 9 de diziembre de 1823 hasta 20 de Marzo de 1824" (1824), ABPL (Lima), Libro de Cuentas de la Archicofradía de N. S. del Rosario (1819-1830), núm. 8064, recibo 7.

22 José García Bryce, "Del barroco al neoclasicismo en Lima: Matías Maestro", Mercurio Peruano (Lima), 480 (1972): 48-68.
} 
antiguos, de que no se aparta toda la obra en lo posible" ${ }^{\text {,2 }}$. Como parte de la capilla, concebida como una unidad con ella, en el cielo raso se ubicaba una apoteosis pintada por Pozo. La obra presentaba un "sotabanco" fingido, el que enmarcaba el Ingreso de los santos peruanos a la gloria, "y el resto se ve poblado de ángeles, todo con escorzo natural y científico, colorido hermoso, y bien templado" 24 .

En la descripción se trasluce el barroquismo del lienzo, remarcado por el uso de trampantojos, como el caso del cornisamento fingido o "sotabanco". Las exigencias ilustradas de la época conducen hacia el uso de una perspectiva ilusionista, el "escorzo natural y científico", y no hacia una simplificación de la composición. El gusto de Maestro por los transparentes se daba a la par con el que sentía por la imitación de mármoles, modo de compensar la inexistencia de estos materiales en obras que intentan seguir modelos de la Antigüedad grecolatina.

\section{Pintura religiosa y programas iconográficos en la primera mitad del siglo XIX}

Una de las preocupaciones ilustradas fue desaparecer las formas de religiosidad popular, tratando de hermanar religión y razón. Frente a los excesos barrocos, como el culto a reliquias o penitencias extremas, se buscó la mesura y la separación de lo religioso y lo secular. En el caso de Lima, si bien para la fecha existe un ataque de los sectores cultos contra las manifestaciones religiosas populares, esto no implica que existiese un bloque homogéneo opuesto a todo tipo de devoción barroca, que algunos sectores de élite mantuvieron. El ataque frontal más explícito contra esto último fue, ciertamente, la serie de escritos elaborados por Toribio Rodríguez de Mendoza contra el culto al Corazón de María, advocación barroca impulsada por los jesuitas y patrona del Colegio de Abogados de Lima ${ }^{25}$. Desde el periódico El Investigador, se habían cuestionado las formas de religiosidad popular, tales como el uso de exvotos o el pedido de limosnas en las corridas de toros. Mas la crítica al culto del Corazón de María iba dirigida a un sector de la élite. De allí la gran cantidad de impresos que produjo este debate y que se

\footnotetext{
${ }^{23}$ Descripción del Cementerio General mandado erigir en la Ciudad de Lima por el Exc ${ }^{\text {mo }}$ Señor Don José Fernando de Abascal y Sousa (Lima: Casa Real de Niños Expósitos, 1808), Av.

${ }^{24}$ Ibídem, Br-Bv.

${ }^{25}$ Un interesante estudio de la polémica es el del Dr. Fernando Romero. Fernando Romero, Rodríguez de Mendoza: hombre de lucha (Lima: Arica, 1973), 308-316.
} 
iniciaron con el "Artículo Comunicado" de Toribio Rodríguez de Mendoza, publicado en El Investigador de Lima, el 28 de agosto de $1813^{26}$.

Ambos, críticos o defensores del Corazón de María, apelan a la razón en sus argumentos. Pero el debate se centra, más allá del culto a aquella advocación, en la pertinencia o no del símbolo en la pintura religiosa, frente a la claridad neoclásica que exige simplicidad en los mensajes. La Ilustración, en su ataque contra la religiosidad barroca, tildada de supersticiosa, arremeterá contra el misticismo y su lenguaje hermético pleno de símbolos, totalmente contrario al pragmatismo y univocidad neoclásicas, y claramente vinculado con la estética barroca tan despreciada por los ilustrados. Del lado opuesto, la defensa del Corazón de María es la de la validez del lenguaje simbólico como medio más apropiado para transmitir lo inefable, lenguaje relacionado con el de las Escrituras:

La Alegoría en todos los pasages de escritura relativos a la profunda, y alta sabiduría, que es la theología mystica, no es causa fatal de sedicion, ni fanatismo ${ }^{27}$.

El pedido de ortodoxia y univocidad hecho por Rodríguez de Mendoza será un ataque a la multiplicidad de lecturas abierta por el uso del simbolismo barroco. Al despojar a las imágenes religiosas de cualquier significado que vaya más allá de su aspecto puramente formal, criticará a los defensores del Corazón de María por "descuartizar" a la virgen al venerar su corazón, y en este mismo sentido mirará como indecentes las representaciones de la lactación de santos ${ }^{28}$. La postura oficial ante este debate se evidencia en la presencia del Virrey Abascal en la consagración del Colegio de Abogados al Corazón de María. El arzobispo, a su vez, aprobará el folleto escrito por José Manuel Bermúdez, quien para defender el culto acudirá, nuevamente, al símbolo:

[...] el corazón es la parte mas noble y principal del viviente: la primera que se anima y la última que muere, el principio de la vida, la oficina de los espíritus donde el alma exercita sus principales operaciones ${ }^{29}$.

\footnotetext{
${ }^{26}$ Toribio Rodríguez de Mendoza, "Defensa de la carta publicada en El Investigador, $\mathrm{N}$. 59”, en Los Ideólogos. Toribio Rodríguez de Mendoza (Lima: Comisión Nacional del Sesquicentenario de la Independencia del Perú, 1972), 237-240.

${ }^{27}$ Bernardo Sáenz, Apología caritativa, pía y racional de las lágrimas de María Santísima, y del piadosísimo ajuar de Santa Rosa, inventada por una ardiente caridad para celebrar el nacimiento del Hijo de Dios (Lima: José Gonzáles, 1814), 9v.

${ }^{28}$ Rodríguez de Mendoza, Defensa de la carta, 324.

${ }^{29}$ José Manuel Bermúdez, Manifiesto sobre el debido culto de los Corazones de Jesús y María (Lima: Imprenta de los Huérfanos, 1813), 20. La atribución a Bermúdez se basa en Romero, Rodríguez de Mendoza, 310.
} 
Tampoco en la élite se observa una negación absoluta de prácticas barrocas, sino su uso atemperado por la influencia del discurso ilustrado. Si Toribio Rodríguez de Mendoza, al cuestionar la práctica de mortificaciones y del "ajuar de Santa Rosa", en 1813 señala que "No todo lo admirable que practican los santos, principalmente las santas, pueden y deben (sic) ser objeto de imitación", Manuel de Urrismendi llamará a la imitación de la santa en un sermón dado en la Catedra ${ }^{30}$. A medida que la crisis del orden colonial se agudice, los sermones tomarán un carácter escatológico y se recurrirá a las prefiguraciones barrocas. Así, la invención de la Cruz, la victoria de Constantino sobre Majencio y el paganismo se equiparan -en un clima peligroso para la Iglesia y el orden social- a la invención de la Cruz de Huamantanga y al llamado a una vida piadosa para el triunfo de la religión ${ }^{31}$.

Peralta Ruiz ha señalado el impacto de la invasión francesa a España en el medio limeño. La defensa de la causa de Fernando VII produjo una abundancia de impresos de carácter político, que entre 1808 y 1810 desplazaron a los de corte religioso en las imprentas limeñas ${ }^{32}$. A partir de estos años se asiste a un aumento de la autoridad virreinal y al control estricto de las publicaciones. La causa de Fernando VII además motivó un reforzamiento de las relaciones entre la Iglesia y el virrey, y entre este y la élite local por medio de la política de Concordia Española en el Perú, que buscó la conciliación de intereses peninsulares y locales ${ }^{33}$.

Así, en la evidente sacralización del discurso monárquico en Lima durante el gobierno de Abascal, en especial luego de la restauración de Fernando VII, se apelará a los santos locales como frutos de la concordia entre españoles y criollos. La abundancia de lienzos con santos peruanos para la fecha pareciera estar relacionada con la política de Concordia Española en el Perú (1809-1815) llevada a cabo por el virrey Abascal, al intentar conciliar los intereses peninsulares y criollos frente a las insurrecciones de distintos puntos de América del Sur. Los grandes

30 Rodríguez de Mendoza, Defensa de la carta, 324; Manuel Antonio de Urrismendi, Sermón Panegírico que en honor y celebridad de la gloriosa virgen Santa Rosa patrona de la América Meridiona [...] (Lima: Imprenta de los Huérfanos, 1812), 13. El "ajuar de Santa Rosa" era el conjunto de oraciones con las que las monjas obsequiaban trajes simbólicos al Niño Jesús.

${ }^{31}$ Manuel Antonio de Urrismendi, Sermón panegírico moral al misterio de la invención de la Santa Cruz, que en la solemne festividad con que los mayordomos españoles honraron la memoria de la prodigiosa invención del Santo Cristo de Huamantanga, según creencia piadosa, dixo en su santuario el día 3 de mayo de 1816 el D.D. Manuel Antonio de Urrismendi, cura y vicario de la doctrina de Atabillos Baxos en la provincia de Canta, ed. Bernardino Ruiz (Lima, 1816).

${ }^{32}$ Peralta, En defensa, 43-46.

33 "Mediante la política de la concordia Abascal cedió a la élite peruana espacios de poder a cambio del compromiso de la misma de sostener el fidelismo y financiar la campaña militar contra las Juntas de Gobierno rebeldes." Peralta, En defensa, 23. 
lienzos de la Catedral de Lima, atribuidos a Maestro, podrían fecharse entre los años de gobierno de este virrey (1806-1816), ya que sabemos que composiciones con una temática parecida, como El ingreso de los Santos Peruanos a la gloria, de la capilla del Cementerio, fueron elaboradas durante estos años ${ }^{34}$. Afín a su labor de diseño, Maestro debió idear estos programas iconográficos, sin que necesariamente todos los lienzos sean de su mano.

Evidencia del uso político de las artes el comentario que apareció en la Minerva Peruana del 4 de junio de 1808, donde se explica una alegoría ubicada en la portada de Maravillas, el león de España que trae a América la cruz de la religión, "y la establece y defiende por medio del sable de la conquista", alegoría a tono con el programa iconográfico fidelista de la Catedral. La portada, realizada por Pedro Antonio de Molina, asumía el motivo del capitel planteado por Luis Le Clerc ${ }^{35}$. Por eso sorprende que líneas más abajo se lea:

[...] el símbolo del Leon, los dos mundos, etc., es uno de los adornos sacados de nuestra religión y nuestras conquistas, los quales quiere sustituir un español de singular mérito, en el sexto orden de arquitectura que ha inventado, a los adornos de los otros órdenes; adornos que todos consisten en alusiones a las divinidades paganas ${ }^{36}$.

No es poco probable que el autor se refiera al Orden Español de Arquitectura, tratado en el que Luís de Lorenzana planteó un nuevo orden arquitectónico, cuya característica principal es un capitel con plumas y una venera vertiendo agua sobre

\footnotetext{
${ }^{34}$ La fecha de ejecución de estos grandes lienzos murales es posterior a 1805 , ya que no los menciona Bermúdez entre las obras realizadas con patrocinio del Arzobispo Gonzáles de la Reguera: "se colocaron las graciosas pinturas del Apocalipsis, Nacimiento, san Gregorio, santo Toribio". José Manuel Bermúdez, Fama Póstuma del Excelentísimo e Ilustrísimo Señor Doctor Don Juan Domingo Gonzáles de La Reguera (Lima: Imprenta Real de los Huérfanos, 1805), 92.

${ }^{35}$ Luís Eduardo Wuffarden, "Avatares del Bello Ideal. Modernismo clasicista versus tradiciones barrocas en Lima, 1750-1825", en Visión y símbolos: del virreinato criollo a la república peruana (Lima: Banco de Crédito del Perú, 2006), 133.

36 "Contestación a la carta inserta en la Minerva número 26", Minerva Peruana (Lima), 27 (4 de junio de 1808): 185. Un ejemplo claramente barroco relacionado con Maestro es la estampa realizada por la fundición de la campana Santo Toribio, completamente anacrónica, al parecer del siglo XVII (GX/769.85/S). Hay que señalar además la relación entre el Retablo Mayor de la Iglesia del Milagro atribuido a Maestro por García Bryce. Bryce, "Del barroco", 56. Y el túmulo rococó de María Amalia de Sajonia, levantado en Lima en 1761 y llevado a la estampa por Camacho (para la lámina del túmulo véase Ricardo Estabridis Cárdenas, El grabado como documento histórico artístico en Lima virreinal (siglos XVI-XIX) (Lima: Universidad Nacional Mayor de San Marcos, 2002), 262263. El estudio del doctor Estabridis resulta necesario por remitirse al grabado virreinal.
} 
ellas, alusión a la conquista y evangelización de América por España ${ }^{37}$. O quizás se refiera al Orden Sacro o tratado de arquitectura escrito por Matías Maestro, desaparecido en la actualidad. Se sabe que Maestro utilizó estos símbolos, como en los capiteles del retablo mayor de la Iglesia de Santo Domingo en Lima (1807), donde recurrió al motivo del León y los penachos emplumados, símbolos respectivos de España y América (Figura 3) ${ }^{38}$. En cualquiera de los dos casos, es visible que la postura oficial busca la homogenización estilística al no cuestionar la necesidad de una normativa arquitectónica. Sin embargo, se intenta despojar de cualquier sentido laicista a los órdenes clásicos, reemplazándolo con un lenguaje simbólico de contenidos monárquico-religiosos.

\footnotetext{
${ }^{37}$ Wuffarden. "Avatares", 133-136.

38 “[...] el precioso tratado de arquitectura que compuso con el título de Orden Sacro, cuya obra revela el gusto exquisito de su genio y su decidida consagración al bien público, su anhelo por el progreso de las artes, lo que, para decirlo de paso, manifiesta que el catolicismo y sacerdocio también saben apreciar los adelantos materiales, y trabajar con actividad para obtenerlos, cuando estos no se hallan en oposición con las virtudes cristianas". Juan Ambrosio Huerta, Traslación a dos mausoleos de los restos de los finados señores doctor don Matías Maestro y don Antonio Chacón (Lima: Imprenta del Católico, 1857), 19.
} 
Figura 3

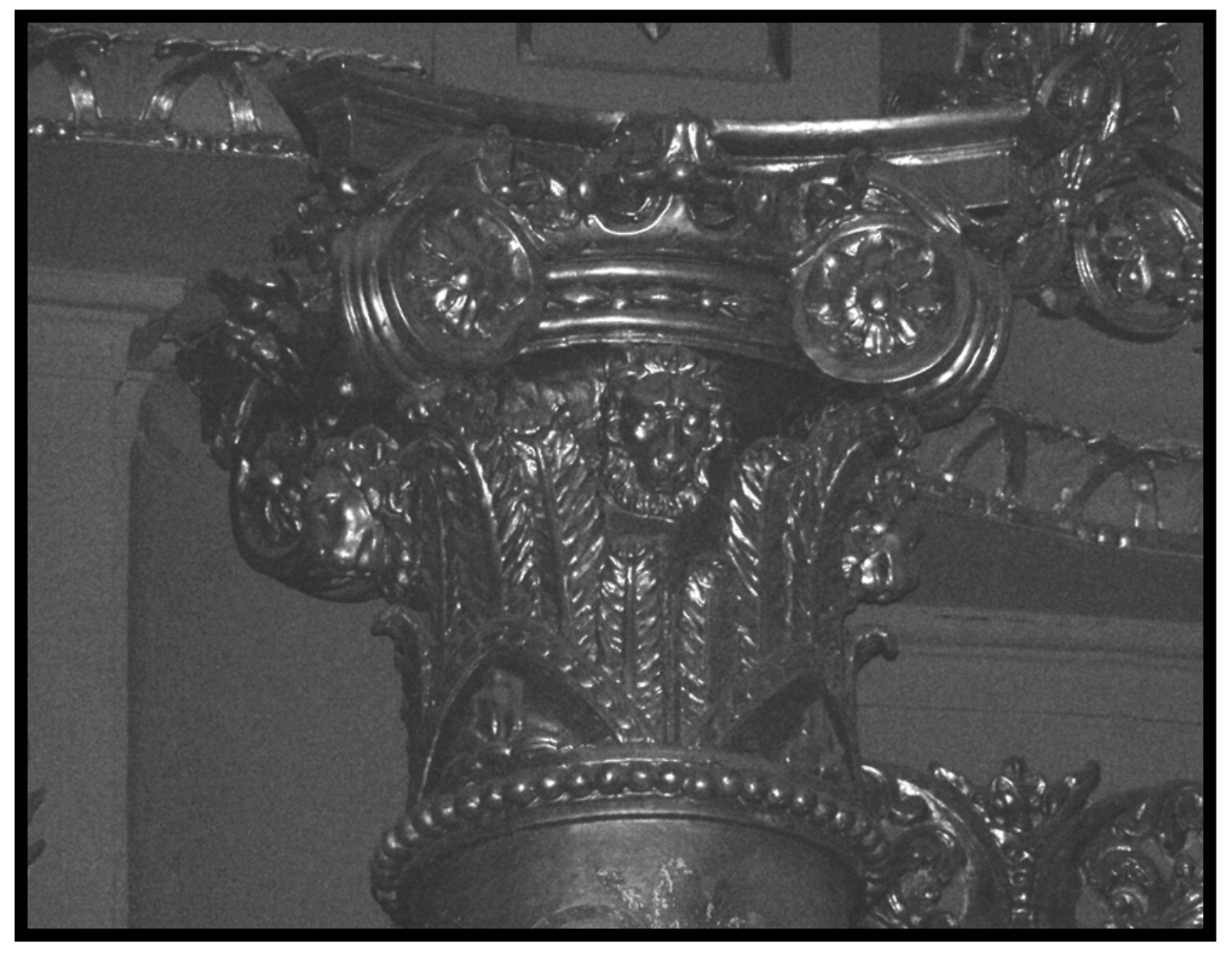

Matías Maestro. Retablo mayor de la iglesia de Santo Domingo (capitel). Lima, 1807. 
Aquí es interesante señalar la disputa por la construcción de una de las torres de la Catedral de Arequipa, ya que la discusión se centra en el carácter retórico de las artes y las formas distintas de concebir el "buen gusto". Bernardo de Gamio, síndico procurador general, denuncia la construcción de la nueva torre por no estar en consonancia con la torre antigua y, en consecuencia, por no existir la simetría tan cara a la estética clasicista. Significativamente, la defensa de la simetría de las dos torres se fundamenta, para Gamio, en la tradicional concepción simbólica de la estructura física de la iglesia como cuerpo:

El cuerpo del hombre obra del arquitecto divino es el mejor modelo de la arquitectura civil [...] Hágase pues la aplicación a las dos Torres Colaterales, que son brazos levantados del cuerpo de la Iglesia ${ }^{39}$.

Sin embargo, Francisco Xavier Echevarría y Santiago Bullota, respectivamente síndico y arcediano de la Catedral, despojan de cualquier sentido metafórico o sacro a la construcción al señalar que el

[...] que las torres sean brazos levantados del cuerpo del Templo es niñería o dislate. Las torres son edificios que en los Templos se levantan para la colocación de campanas ${ }^{40}$.

Las actitudes del síndico y el arcediano de la Catedral de Arequipa -quienes también argumentan que "El exercicio de las artes no consiste en imitar lo antiguo, sino en cultivarlo a la perfeccion, y añadir otras nuevas [reglas]" ${ }^{\prime 4}$ - evidencian un sentido práctico y laicista, un gusto moderno que desacraliza los contenidos de la estructura arquitectónica y su ornamentación, y plantean la "novedad" como principal valor estético. Se opone a ellos la defensa de la tradición, si bien de la entendida por clásica y no de la local, visible en Gamio o en Maestro, para quienes la adopción de normas "racionales" y de "buen gusto" en la arquitectura parte de su sacralización, de su uso retórico y de la justificación de su validez en el pasado ${ }^{42}$.

Los lienzos de la catedral son cuatro: dos en el baptisterio, decorado con trampantojos o arquitectura fingida; uno en la capilla de Nuestra Señora de la Antigua y uno en semicírculo ubicado en el muro testero. En estos lienzos, el fidelismo se imbrica con un discurso de afirmación local que, al detentar a los

39 Intendencia de Arequipa, Sobre fábrica de la nueva Torre de la Yglesia Cathedral, Manuscritos D5960 (Lima: Biblioteca Nacional del Perú, 1806-1808), 1r.

${ }^{40}$ Ibídem, $11 \mathrm{r}$.

${ }^{41}$ Ibídem (resaltado del autor).

${ }^{42}$ Señala Lempérière en su estudio sobre México que lo moderno se basa en la formación de una cultura laica, general a todos los individuos, opuesto a una sociedad compuesta por instituciones corporativas, que reproducen toda una cultura festiva que define los espacios públicos sacralizándolos. Lempérière, "De la república", 337. 
santos peruanos como muestra de las excelencias locales, se sustenta precisamente en la conquista y la defensa del monarca. La paridad local con la Metrópoli se establece en base a la fidelidad con la Corona. Esto se hace explícito en el pedido de la mediación real, realizado por el Cabildo Metropolitano en 1816, para elevar al arzobispo de Lima a la dignidad de cardenal, al sustentarse en la necesidad de que:

[...] esta Santa Iglesia única del Perú en los principios de su conquista; esa Santa Iglesia Metropolitana, que entre sus muy grandes y recomendables Arzobispos presentó en los altares, por una de sus primicias, al Santo Mogrovejo [fuera de los otros dos, el Santo Solano y Santa Rosa de Santa María, que corresponden al Arzobispado y a la ciudad]; esta Iglesia que ha sostenido los dogmas y establecido los principios de sana moral en cuatro Concilios provinciales, sea condecorada para siempre con la Púrpura Cardenalicia $[. .]^{43}$

Así, los santos peruanos se yerguen como protectores del orden colonial, ya que son productos de él, en una relación de comunión de intereses de lo criollo y la Metrópoli. En el discurso de Justo Figuerola por la invasión napoleónica de España, encargado por la Archicofradía del Rosario de Españoles e impreso en 1808, se lee:

No solo hemos orado nosotros: el pontífice del Perú, Toribio, nuestro amado Onías, acreedor al mismo elogio que este sumo sacerdote: la casta Virgen Rosa, que compareció ante el esposo con la vestidura blanca, desfallecida por la fuerza de su puro y encendido amor: el Apóstol Solano que iluminó con sus palabras de vida a los infelices que en estas regiones yacían recostados a la funesta sombra del árbol de la muerte, han orado, y están con las manos levantadas al trono del Cordero sin mancha, rogando por el pueblo que edificara con sus exemplos, por el Monarca que lo rige, $\mathrm{y}$ por las armas que defienden sus santos derechos ${ }^{44}$.

La abundancia de imágenes de Santa Rosa pintadas para la fecha, una de ellas con certeza obra de José del Pozo (Figura 4), pareciera estar igualmente vinculada con

43 José Manuel Bermúdez, Anales de la catedral de Lima ([1824] Lima: Imprenta del Estado, 1900), 418. El pedido del Cabildo Metropolitano era la concreción no realizada de una serie de privilegios obtenidos para el arzobispo Bartolomé de las Heras, como la Gran Cruz de Carlos III y la de Isabel la Católica, basada en la defensa y colaboración con el monarca realizada por el prelado durante la invasión napoleónica a España. El informe iba remitido también por el Virrey Abascal, ya de partida para la corte.

${ }^{44}$ Justo Figuerola, Noticia de las Devotas Rogativas con que la Ciudad de Lima imploró el auxilio divino en las actuales circunstancias de la Monarquía (Lima: Imprenta de los Niños Expósitos, 1808), 47. 
la defensa del orden colonial, ya que el símbolo estratégico de esta Concordia Española era Rosa de Lima ${ }^{45}$. Hay un espíritu afín entre los lienzos de la Catedral y los sermones contra la invasión francesa a España, o contra las insurrecciones de Buenos Aires. Así, en el sermón de la institución del Regimiento de Concordia, se señala:

[...] las Indias no olvidarán jamás lo que deben al Europeo, y su memoria será siempre contestada de las dulces efusiones del corazón. Por que ¿quién las sacó de las tinieblas de la gentilidad? ¿Quién las cultivó y formó en el bello órden en que aparecen? ¿Quién las adiestró en las Artes y las instruyó en las ciencias?",46

Este párrafo se vincula con los dos lienzos del baptisterio de la catedral. Uno, semicircular y ubicado en el baptisterio, alude al papel de la Iglesia limeña (una mujer con mitra y el cáliz con la sierpe en un ángulo del lienzo) en la evangelización de los indios (La Iglesia limeña redentora de los indios). La corona de plumas al pie de la pila bautismal, si bien no necesariamente una alusión al Orden Español, indica la forma en que el contenido ideológico de este orden es modificado por las elites locales, al asumirse ellas como las que llevaron a cabo la evangelización (y la conquista) de estos territorios. Debajo de este, otro lienzo representa los distintos santos y bienaventurados como Los frutos de la Iglesia limeña (véase el angelito con una lima en la mano) que la conquista española ha producido en su suelo ${ }^{47}$.

\footnotetext{
${ }^{45}$ Ramón Mujica, "El Ancla de Rosa de Lima: Mística y política en torno a la Patrona de América”, en Santa Rosa de Lima y su Tiempo (Lima, Banco de Crédito del Perú, 1995), 190. El retablo mayor de su santuario, obra de Maestro donde se ubica el lienzo de José del Pozo, presenta columnas en el orden español de Lorenzana.

${ }^{46}$ Ignacio Gonzáles Bustamante, Sermón de Acción de Gracias por la institución del Ilustre Regimiento de Concordia del Perú (Lima: Casa de Niños Expósitos, 1811), 14.

${ }^{47}$ El lienzo también está en relación con un fragmento del Canto VII de la Lima Fundada de Pedro de Peralta, la aparición a Pizarro de un templo con los santos y venerables peruanos, en una prolija enumeración que va desde la octava CLXXXIII hasta la CCL. Véase Pedro de Peralta y Barnuevo, Lima Fundada y Conquista del Perú (Lima: Imprenta Sobrino y Bados, 1732), Canto VII.
} 
Figura 4

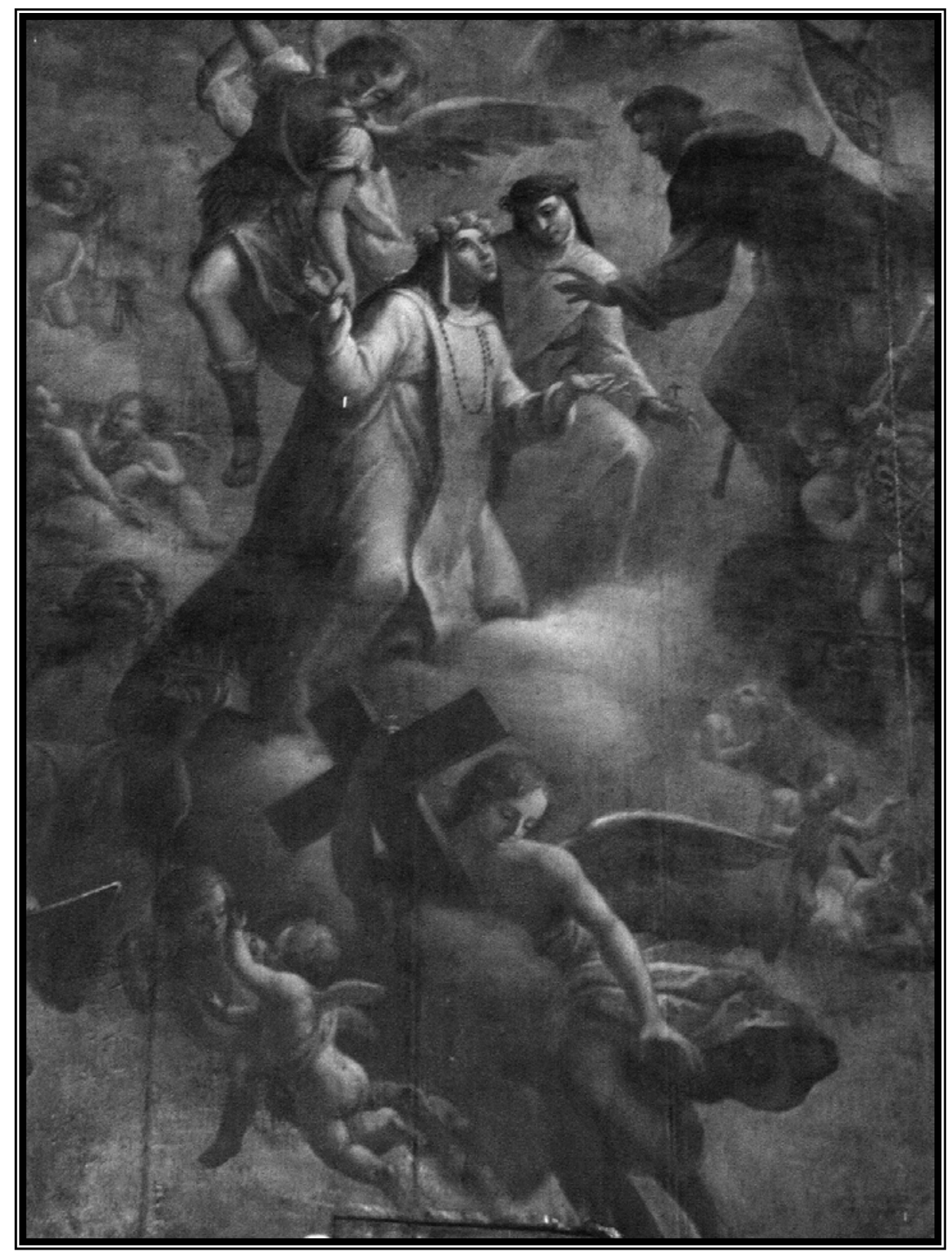

José del Pozo. Apoteosis de Santa Rosa (detalle). Lima, década de 1810. Iglesia de Santa Rosa de los Padres, Lima. 
Sin referencias impresas, mas otra muestra muy clara de la actitud de la época, es una alegoría existente en la capilla de la Antigua de la Catedral, seguramente encargo de la Universidad de San Marcos, que representa una apoteosis de la ortodoxia de este centro de estudios. El evangelista San Marcos, elevado por un ángel, tiene bajo él a los Padres de la Iglesia, San Luis Gonzaga, San Buenaventura, Santo Tomás y Santa Rosa. En suma, en La Universidad de San Marcos defensora de la Escolástica, Santa Rosa es el fruto que las Indias dieron por la conquista española ${ }^{48}$.

El aire de familia que tienen en común todas estas composiciones -sin ser necesariamente de un mismo pintor- con las obras de Pozo, es más notorio si se contrapone a la producción pictórica local. Es evidente la ruptura que genera esta pintura "progresista", de un academicismo importado, frente a la labor de los artistas locales. La homogenización estilística reflejo del absolutismo traerá como consecuencia la subordinación de las manifestaciones artísticas locales a las de la Metrópoli. Las grandes alegorías y apoteosis que se prodigarán en Lima durante las dos primeras décadas del siglo, desde el palacio del virrey hasta la catedral, no solo transmitirán contenidos oficiales, sino que su factura, distinta a la de la tradición pictórica limeña, será elevada a paradigma por el gusto oficial y de élite ${ }^{49}$.

Es lamentable la desaparición del retrato de Simón Bolívar realizado por José del Pozo, para el Tribunal del Consulado. Pero existen otros dos del Libertador, ambos de 1825 , los cuales ejemplifican el cambio de gusto generado por la Independencia, que dejará atrás al pintor sevillano, y retoman la tradición pictórica local. Los convencionalismos del retrato cortesano limeño, establecidos desde Cristóbal Lozano, se hacen presentes en la obra de Pablo Rojas (existente en el Museo Nacional de Arqueología, Antropología e Historia del Perú, de Pueblo Libre): el cortinaje rojo, la vista exterior, la columna, la cartela, dispuestos para evidenciar la posición social del retratado. Frente a ello, aún con una factura heredera de la tradición de los talleres coloniales, resulta completamente innovador para el medio limeño el retrato de Simón Bolívar hecho por José Gil de Castro, en la actualidad en el Palacio Federal de Caracas. Gil prescinde completamente del atrezzo cortesano, y ubica la imagen del Libertador sola sobre un fondo verdoso, con lo que adquiere una presencia monumental. Estos fondos ya habían sido utilizados por Gil en Santiago y resultaban más adecuados para el gusto republicano al eludir cualquier referencia corporativa, aparte de las de la propia figura del retratado, y remarcar la austeridad del nuevo orden político. Si Gil, partícipe del sentimiento

48 Sobre el último lienzo, La Consagración de la Catedral de Lima, se tiene la confirmación documental de la autoría de Maestro, y de su donación por Pedro del Toro (1847). Archivo Arzobispal de Lima (Lima), Papeles Importantes, exp. 16, leg. $19^{\mathrm{a}}$.

49 Presidía la Sala de Corte del palacio un "Lienzo alegórico" pintado por Pozo en 1816. Pedro Ugarteche, "Inventario del Palacio del Virrey en 1821", Revista Histórica (Lima), 30 (1967):404. 
republicano, destaca al "héroe ciudadano" Bolívar, Rojas lo retrata como un noble, continuador de la serie de gobernantes virreinales.

El retrato de Rojas fue encargado a este pintor por la municipalidad en 1825. Más originales que el retrato son los dos lienzos alegóricos realizados por el mismo pintor, composiciones de las que no quedan mayores referencias que un comentario en la Gaceta del Gobierno d0el Perú del 30 de octubre de 1825, y una estampa (Simón Bolivar recibe del Inca Viracocha la maqueta del Templo del Sol) grabada en cobre por Marcelo Cabello existente en el Museo de Arte de Lima ${ }^{50}$. Así, según la Gaceta, se veían:

[...] en dos diversos y vistosos transparentes al jeneral Sucre en el momento de decidir la batalla de Ayacucho, cuando los cuerpos españoles se precipitaban de las alturas a envolver por todas partes nuestro ejercito; $y$ el jenio del Perú, representado en el Inca Viracocha revestido de los atributos del imperio y seguido de las virjenes del Sol, que llevaban en sus puras manos una ancha cinta blanca y encarnada, ofreciendo el templo, en que adoraban este astro, a Bolívar que, cabalgando en un sobervio caballo, pisaba un suelo sembrado de cadáveres españoles; viéndose a distancia parada la Libertad en un pico de los Andes ${ }^{51}$.

Por la estampa conservada observamos la mediocridad de la composición, probablemente simplificada por Cabello al trasladarla al metal. Un detalle más importante es la representación intencional de lo incaico a la manera de imágenes clásicas. Su idealización se corresponde con la búsqueda de referentes por parte de la nación criolla revistiendo a los incas con detalles clasicistas, y por tanto, ajenos a lo indígena contemporáneo. Sin embargo, estas representaciones, que pretenden aludir a imágenes grecolatinas, en la práctica solo asumen los motivos clásicos de forma decorativa en un espacio carente de perspectiva y proporción. Pareciera que esta es la proyección visual de las constantes referencias en los diversos poemas de la época a un pasado incaico.

\section{Epílogo}

En 1826, José del Pozo, nuevamente bajo la protección de Maestro, director de la Beneficencia de Lima, trabajaba de escenográfo para el Coliseo de Comedias de esta ciudad, actividad que ya había ejercido por lo menos en 1816. La alta estima que del trabajo de Pozo se tenía en la capital es visible en las distintas propuestas

\footnotetext{
${ }^{50}$ Natalia Majluf, "Colección permanente. Adquisiciones 2000", Boletín del Museo de Arte de Lima (Lima), núm. 249, año 22 (enero 2001).

51 "Fiestas Cívicas", Gaceta del Gobierno del Perú (Lima), 35, tom. 8 (30 de octubre de 1825): 1 .
} 
que se hicieron para arrendar el local. Por la "Razon q. manifiesta la reforma hecha en la Casa Coliseo", dada por Zúñiga, desde marzo a agosto de 1826, se indican las obras de pintura elaboradas entre estas fechas:

Decoraciones / Una Casa de Campo de dos terminos pintada p. el profesor Poso / Una Sala brillante para los Dramas modernos $\mathrm{p}^{\mathrm{r}}$ el mismo / Un Atrio magnífico para piesas trágicas, retocado absolutam $^{\text {te }} \mathrm{y}$ aumentados sus bastidores, por el mismo profesor / Un rompimiento y bambalinas por Ydem $^{52}$.

El texto evidencia el carácter barroco de las decoraciones en el que Del Pozo estaba especializado. Tanto así que en las distintas propuestas señalan que el sevillano era el de mejor gusto o "el único profesor que hay en el País, de esta clase de obras" ${ }^{, 53}$. El uso de trampantojos y efectismos barrocos parece que se desplazó a las decoraciones teatrales para la fecha, lo que produjo que Del Pozo se pudiera adecuar al nuevo orden republicano. Pero el cambio de régimen debe haber sido bastante adverso a aquellos artistas de menor rango, dedicados a la elaboración de obras religiosas. Puede ser este el caso de Domingo Urrueta, hijo de Joaquín Urrueta, quien en su testamento del 25 de julio de 1829 afirmaba que a pesar del constante trabajo " $\mathrm{q}$ e he tenido en mi Arte por mi inteligencia y Onrrados procedimientos" se hallaba en la miseria

[...] por las Calamidades que notoriamente estamos esperimentando en esta ciudad en todas las clases que hacen y componen este besindario y aun toda la república $[\ldots]^{54}$.

Los cambios generados por la independencia, entre ellos la derrota de la nobleza criolla $^{55}$, y el relevo del poder a una mesocracia compuesta por militares y burócratas, se reflejará en el desplazamiento de las esferas oficiales de José del Pozo, y de los pintores locales acostumbrados a trabajar en los esquemas del retrato cortesano limeño. Paradójicamente, en la República, la "vanguardia" pictórica

${ }^{52}$ Ibídem, fol. $85 \mathrm{r}$.

${ }^{53}$ Ibídem, fols. 97r y $108 \mathrm{v}$. Igualmente en febrero 25 de 1829 , en las condiciones para la subasta de la Casa de Comedias redactados por el licitador don Francisco Fresco, en el punto 5 se señala: "Para el día primero de Abril próximo se hará un Telon de voca del mejor gusto y dos decoraciones nuevas por lo menos; y en el resto del año entrante otras seis; y sucesivamente se renovaran quatro al menos cada año; todo de mano del único Profesor Pintor de teatro $\mathrm{d}^{\mathrm{n}}$ José del Pozo, u otro en su defecto". Francisco Fresco, "Condiciones para la subasta de la Casa de Comedias q $q^{\mathrm{e}}$ hace el Licitad $\mathrm{d}^{\mathrm{n}}$ Fran $^{\text {co }}$ Fresco" (1829), ABPL (Lima), inserto en núm. 8471.

54 "Ignacio Ayllón Salazar", AGN (Lima), Notariales 49, fols. 656v-657r.

${ }^{55}$ Véase Alberto Flores Galindo, La ciudad sumergida. Aristocracia y plebe en Lima, 1760 1830 (Lima, Horizonte, 1990). 
frente al academicismo importado de Pozo, será asumida por José Gil de Castro, pintor formado en la tradición de los talleres virreinales. Su compenetración con los ideales republicanos, visible en el retrato de Simón Bolívar, lo harán el pintor más adecuado para satisfacer el gusto de los grupos de poder ascendentes. Así se explica mejor el desplazamiento de José del Pozo, vinculado con la élite española de la ciudad, trabajador constante para la Archicofradía del Rosario de Españoles y el Tribunal del Consulado, que vio disminuida su importancia luego de la Independencia. A pesar de que existen referencias de la labor del pintor sevillano como retratista, Gil de Castro acaparará los trabajos de este carácter ${ }^{56}$.

Las características que asumió el arte en Lima a inicios del siglo XIX estuvieron determinadas por grandes cambios políticos. En este contexto, pintura o arquitectura cumplieron funciones propagandísticas. De allí la pervivencia de elementos barrocos, plenamente vigentes por su función persuasiva. Pero estos elementos resultaban innovadores en el medio local, por su estilo académico de importación que rompía con las tentativas locales de configurar un academicismo periférico. Por ello no sólo los contenidos eran parte de un discurso oficial, también las formas. El "buen gusto" impuesto por la labor de Matías Maestro y José del Pozo significó la subordinación de las manifestaciones artísticas locales a las de la Metrópoli, al imponerse dos artistas españoles, sin formación local, en el gusto oficial y de élite. Así, en la pintura, el triunfo inicial del academicismo importado de Del Pozo y Maestro prefigurará la ruptura total que la pintura "culta" de mediados del siglo XIX efectuará con la tradición local.

\section{Bibliografía}

\section{Fuentes primarias}

Archivo General de la Nación, Lima, Perú.

Archivo de la Beneficencia Pública de Lima, Perú.

\section{Fuentes secundarias}

Abascal, José Fernando de. "Bando", Minerva Peruana extraordinaria (Lima), 40 (10 de octubre de 1806).

\footnotetext{
${ }^{56}$ Se sabe por la Gaceta del Gobierno del Perú de 1825, que se encargó un retrato de Bolívar a José del Pozo. Tenemos referencias de que Cayetano Pozo, hijo de José del Pozo, ejerció el oficio de pintor en Lima con posterioridad a la muerte de su padre, aunque pareciera no haber poseído mayor relevancia.
} 
“Panteón”. Minerva Peruana (Lima), 1 (6 de enero de 1810): 6-8.

Assunto, Rosario. La antigüedad como futuro. Estudios sobre la estética del neoclasicismo europeo, trad. Zósimo Gonzáles. Madrid: Visor, 1990.

Bermúdez, José Manuel. Fama Póstuma del Excelentísimo e Ilustrísimo Señor Doctor Don Juan Domingo Gonzáles de La Reguera. Lima: Imprenta Real de los Huérfanos, 1805.

- Manifiesto sobre el debido culto de los Corazones de Jesús y María. Lima: Imprenta de los Huérfanos, 1813.

. Anales de la catedral de Lima. [1824] Lima: Imprenta del Estado, 1900.

Bernales Ballesteros, Jorge. "La pintura en Lima durante el Virreinato". En Pintura en el Virreinato del Perú, 31-107. Lima: Banco de Crédito del Perú, 2002.

"Contestación a la carta inserta en la Minerva número 26". Minerva Peruana (Lima), 27 (4 de junio de 1808): 185-186.

Descripción del Cementerio General mandado erigir en la Ciudad de Lima por el Exc $^{\text {mo }}$ Señor Don José Fernando de Abascal y Sousa. Lima: Casa Real de Niños Expósitos, 1808.

Demélas, Marie-Danielle. La invención política. Bolivia, Ecuador, Perú en el siglo $X I X$. Lima: Instituto Francés de Estudios Andinos; Instituto de Estudios Peruanos, 2003.

Estabridis Cárdenas, Ricardo. El grabado como documento histórico artístico en Lima virreinal (siglos XVI-XIX). Lima: Universidad Nacional Mayor de San Marcos, 2002.

Figuerola, Justo. Noticia de las Devotas Rogativas con que la Ciudad de Lima imploró el auxilio divino en las actuales circunstancias de la Monarquía. Lima: Imprenta de los Niños Expósitos, 1808.

"Fiestas Cívicas". Gaceta del Gobierno del Perú (Lima), 8, núm. 35 (30 de octubre de 1825): 1-3.

Flores Galindo, Alberto. La ciudad sumergida. Aristocracia y plebe en Lima, 17601830. Lima: Horizonte, 1990. 
García Bryce, José. "Del Barroco al Neoclasicismo en Lima: Matías Maestro". Mercurio Peruano (Lima), 480 (1972): 48-68.

Gonzáles Bustamante, Ignacio. Sermón de Acción de Gracias por la institución del Ilustre Regimiento de Concordia del Perú [...]. Lima: Casa de Niños Expósitos, 1811.

Huerta, Juan Ambrosio. Traslación a dos mausoleos de los restos de los finados señores doctor don Matías Maestro y don Antonio Chacón. Lima: Imprenta del Católico, 1857.

Intendencia de Arequipa. Sobre fábrica de la nueva Torre de la Yglesia Cathedral, manuscritos D5960. Lima: Biblioteca Nacional del Perú, 1806-1808.

Kusunoki Rodríguez, Ricardo. "De Ruiz Cano a Unanue: Arte y reivindicación criolla en Lima (1755-1806)". Dieciocho (Virginia), 29, núm. 1 (2006): 107-120.

. "Barroco y pintura limeña a inicios del siglo XIX". Uku Pacha. Revista de Investigaciones históricas (Lima), año 5, núm. 9 (2006): 101-110.

Lempérière, Annick. "De la república corporativa a la nación moderna. México (1821-1860)". En Inventando la nación. Iberoamérica. Siglo XIX, eds. Antonio Annino y Francois-Xavier Guerra, 316-346. México: Fondo de Cultura Económica, 2003.

Leuro, Juan José y Juan Genaro Villota. Cuenta presentada por los comisionados Juan Genaro Villota y Juan José de Leuro, manuscrito D5979. Lima: Biblioteca Nacional del Perú, 1816.

Loayza, Fray Pedro. Oraciones que se pronunciaron el diez y el diez y seis de julio del presente año [...]. Lima: Imprenta de los Huérfanos, 1811.

Macera, Pablo. La pintura mural andina. Siglos XIV-XIX. Lima: Milla Batres, 1993.

Majluf, Natalia. "Colección permanente. Adquisiciones 2000". Boletín del Museo de Arte de Lima (Lima), núm. 249, año 22 (enero 2001).

Mujica, Ramón. "El Ancla de Rosa de Lima: Mística y política en torno a la Patrona de América". En Santa Rosa de Lima y su Tiempo, 53-211. Lima: Banco de Crédito del Perú, 1995. 
. "Arte e identidad: las raíces culturales del Barroco peruano". En El Barroco Peruano, 1-57. Lima: Banco de Crédito del Perú, 2002.

Novajas, Casimiro. Rasgo Épico. El Vergel Dominicano. Lima: Casa Real de Niños Expósitos, 1807.

Peralta y Barnuevo, Pedro de. Lima Fundada y Conquista del Perú. Lima: Imprenta Sobrino y Bados, 1732.

Peralta Ruiz, Víctor. En defensa de la Autoridad: Política y cultura bajo el gobierno del virrey Abascal, Perú 1806-1816. Madrid: Consejo Superior de Investigaciones Científicas; Instituto de Historia, 2002.

Reglamento provisional acordado por el Ecmo. Señor Don José Fernando de Abascal y Sousa con el Illmo. Señor Doct. D. Bartolomé María de las Heras para la apertura del Cementerio General de esta ciudad. Lima: Real Casa de Niños Expósitos, 1808.

Rodríguez de Mendoza, Toribio. "Defensa de la carta publicada en El Investigador, N. 59”. En Los ideólogos. Toribio Rodríguez de Mendoza. Lima: Comisión Nacional del Sesquicentenario de la Independencia del Perú, 1972.

Romero, Fernando. Rodríguez de Mendoza: hombre de lucha. Lima: Arica, 1973.

Sáenz, Bernardo. Apología caritativa, pía y racional de las lágrimas de María Santísima, y del piadosísimo ajuar de Santa Rosa, inventada por una ardiente caridad para celebrar el nacimiento del Hijo de Dios, ed. don José Gonzáles. Lima, 1814.

Sarmiento, Ernesto, El arte virreinal en Lima. Lima: Arica, 1971.

Ugarteche, Pedro. "Inventario del Palacio del Virrey en 1821". Revista Histórica (Lima), 30 (1967): 400-411.

Urrismendi, Manuel Antonio de. Sermón Panegirico que en honor y celebridad de la gloriosa virgen Santa Rosa patrona de la América Meridiona [...]. Lima: Imprenta de los Huérfanos, 1812.

. Sermón panegírico moral al misterio de la invención de la Santa Cruz, que en la solemne festividad con que los mayordomos españoles honraron la memoria de la prodigiosa invención del Santo Cristo de Huamantanga, según creencia piadosa, dixo en su santuario el día 3 de mayo de 1816 el D.D. Manuel Antonio de Urrismendi, cura y vicario de la doctrina de 
Atabillos Baxos en la provincia de Canta, ed. Bernardino Ruiz. Lima, 1816.

Wuffarden, Luis Eduardo. "Avatares del Bello Ideal. Modernismo clasicista versus tradiciones barrocas en Lima, 1750-1825". En Visión y símbolos: del virreinato criollo a la república peruana, 113-159. Lima: Banco de Crédito del Perú, 2006.

Fecha de recepción: 27 de febrero de 2006.

Fecha de aprobación: 14 de junio de 2006. 